\title{
Autoria e plágio na Internet: Uma leitura discursiva
}

\author{
Marci Fileti Martins \\ UNISUL
}

\section{Carolina Neotti}

UNISUL

\begin{abstract}
Resumo
A discussão proposta busca compreender a posição do aluno enquanto autor nos trabalhos científicos de graduação, as chamadas monografias. Para isso, analisaremos a relação desses trabalhos monográficos com os materiais retirados da internet que vão compô-los, mas que não são indicados como fonte de pesquisa pelo aluno. Para essa discussão, privilegiaremos a compreensão da relação que se estabelece entre os discursos pedagógico (DP), científico (DC) e o que denominaremos discurso acadêmico (DA), os quais constituem as relações interdiscursivas na universidade e determinam o funcionamento da autoria nas monografias.
\end{abstract}

Palavras-chave: Discurso pedagógico, discurso acadêmico, autoria, plágio, internet.

\section{INTRODUÇÃO}

Este trabalho levanta questões sobre forma de constituição da autoria do aluno, examinando, especificamente, a sua posição enquanto produtor de trabalhos de conclusão de curso de graduação (monografias). Destacamos aí, a relação desses trabalhos monográficos com a internet, a qual foi usada como fonte de pesquisa. Entretanto, os materiais (artigos científicos) pesquisados na rede que vão compor as monografias não são indicados como fonte de pesquisa pelo aluno. Esse procedimento, que se convencionou denominar plágio, funda um problema para as instituições de ensino, notadamente para a universidade, já que evidencia a sua dificuldade para construir um espaço de autoria, onde o aluno pode formular suas próprias questões.

Essa situação se mostra contraditória com o papel da universidade que, numa sociedade como a nossa, é uma instituição de prestígio que se legitima como aquela responsável pela produção do conhecimento científico. Essa posição de autoridade e prestígio da universidade é resultado de um processo histórico, político e social, o qual aparece 
apagado para os sujeitos. De fato, a partir de uma perspectiva discursiva (Pêcheux, 1969/1997, 1975/1988; Orlandi, 1996, 1999, 2003), as instituições se constituem por práticas de linguagem, em que o sujeito e o sentido formulado por ele são imaginários, pois são afetados pela ideologia.

A ideologia, pensada nos termos de Pêcheux (1988), não é boa nem má, mas se constitui produzindo uma relação imaginária dos sujeitos com suas condições reais de existência. Em outras palavras, o processo que determina as posições dos sujeitos (aluno/professor/cientista/pesquisador) “construídas ao longo da história e através de relações de poder (políticas) é, na maioria das vezes, apagado, o que faz com que os sentidos aí produzidos se tornem naturalizados e óbvios” (Gallo et al, 2008, p. 4). Além disso, essas posições “óbvias” para os sujeitos já estão prontas para serem assumidas; assim, o sujeito ao ser interpelado pelo discurso pedagógico na universidade, por exemplo, vai produzir sentidos sobre o conhecimento (ciência) a partir desses lugares já prontos e óbvios.

É por isso que, para Pêcheux (1997), há nos mecanismos de todo discurso regras de projeção que estabelecem a relação entre as situações concretas e as representações dessas situações no interior do discurso. Assim, dos discursos que constituem a universidade, destacamos o discurso pedagógico (DP), que determina certo jogo de imagens. Nessa formação imaginária constrói-se um jogo interlocutivo, em que há um sujeito que fala: o professor, que sabe e por isso pode falar e ensinar algo, que é o conhecimento (a ciência). A partir disso, constrói-se a imagem do referente, através de uma terminologia, para um sujeito (aluno) que ouve. A imagem do aluno, neste jogo interlocutivo, é aquela de quem não sabe e por isso deve ouvir mais que falar.

Nesse funcionamento, tudo o que o professor diz se converte em conhecimento legítimo e é o único que autoriza a aprendizagem deste. Assim, os sujeitos, ao ocuparem as posições de professor e de aluno, são determinados por essas representações que fixam dois papéis distintos: a autoridade e o tutelado: "Desenvolvem-se aí tipos de comportamentos que podem variar desde o autoritarismo mais exarcebado ao paternalismo mais doce.” (Orlandi, 2003, p. 31).

Castanho (2000) afirma que desde as primeiras universidades sempre ocorreu um processo de enclausuramento protetor dos corpos docente e discente, ora de um, ora de outro, por vezes de ambos, diante de poderes externos, nomeadamente a Igreja e o Estado e, muito 
particularmente, do primeiro. A universidade, por isso, com a responsabilidade de educar, sempre esteve no bojo das relações de poder e, mesmo sendo a educação hoje, imaginariamente, o pilar do desenvolvimento do conhecimento e da pesquisa científica, vai representar, segundo Chauí (apud Orlandi, 2003), mais que a reprodução de uma ideologia dominante e de relações de poder. Segundo Chauí, a educação é tomada em seu aspecto econômico e a função das instituições de ensino é reproduzir a força do trabalho: "Hoje a educação é encarada imediatamente como capital, produção e investimento que deve gerar lucro social” (apud Orlandi, 2003, p. 28).

De tal modo, o professor que pretende transformar sua prática na sala de aula, evitando os problemas decorrentes de uma postura autoritária em relação a sua posição no sistema de ensino e aprendizagem, encontra-se numa zona de transição de paradigmas (Castanho, 2000). Caso exemplar é o de Paulo Freire que, desde a década de 60, buscava novas perspectivas para a educação. "Educação popular", "pedagogia crítica", "pedagogia da autonomia" são alguns enunciados que remetem a uma tentativa de mudança no sistema educacional. Ao destacarmos aqui a proposta de Paulo Freire (1983, 1985, 1996) enquanto movimento de ruptura, de deslocamentos no sistema educacional, queremos evidenciar as relações que constituem as práticas discursivas da universidade. Esse espaço de ensino e aprendizagem é determinado não somente pelo DP, mas por uma dispersão de discursos: o administrativo, o científico, o jurídico, o da "pedagogia da autonomia", etc. Toda essa interdiscursividade ${ }^{1}$ faz parte das práticas de linguagem da universidade.

Dito isso, vamos propor que a universidade se constitui também por outro discurso que denominaremos acadêmico (DA). O DA se estabelece, sobretudo, por uma relação diferenciada entre os sujeitos professor e aluno, já que diferentemente do DP, o professor não apaga de forma peremptória a voz do aluno com sua autoridade. Nessa posição, o aluno tem espaço para falar, para formular sobre o conhecimento. Além disso, o DA se constitui numa relação de aliança com o discurso científico. Dito de outra maneira, enquanto no DP o professor apaga a voz do cientista, no DA o professor enfatiza sua voz enquanto mediador. A monografia, que tem “como finalidade atender às exigências dos cursos de nível superior,

\footnotetext{
1 Interdiscurso é aquilo que fala antes e que retorna sob a forma do preconstruído, de um já-dito denominado memória discursiva. A partir disso, Maingueneau (1983, 1984 apud Brandão, 2002) afirma que não existe discurso autofundado, de origem absoluta, pois enunciar é se situar sempre em relação a um já-dito que se constitui no Outro do discurso: "um discurso não se inscreve sobre uma página branca; quando ele se constitui, não pode ser senão em um campo já saturado por outros discursos...o novo não pode se enunciar senão por um reagenciamento do que já está lá” (Maingueneau, 1983 apud Brandão, 1998, p. 126).
} 
onde ocorre a primeira necessidade documentada de um trabalho com efeito científico" (Rauen, 1999, p. 238), pode estar materializando essas relações entre professor, aluno e conhecimento, que determinadas pelo DA se constituem de forma mais polêmica.

Assim o trabalho monográfico pode ser um observatório produtivo para discutirmos as questões envolvendo o modo como o aluno universitário se relaciona com a pesquisa, a qual demanda uma certa posição de autoria. De fato, na monografia, o aluno necessita trazer o preconstruído $^{2}$ do discurso científico (DC) e o faz através da identificação da voz do "outro" (cientista/pesquisador) no seu discurso (texto). Contudo, como já destacado, nas monografias analisadas, no que diz respeito a sua relação com os materiais pesquisados na internet, observamos que o aluno apaga o percurso feito por ele na rede quando a utiliza como fonte de pesquisa. O aluno se apropria do texto de outros autores como se fossem seus, ou seja, não explicita, como é usual num texto científico, os autores das obras consultadas. Para Gallo (2004, p. 11), esse procedimento (plágio) não é um fato em si, nem evidente, nem transparente, mas um sintoma, a marca da posição que o sujeito ocupa ao realizar o trabalho acadêmico:

A pergunta que cabe aqui é: por que o aluno ocupa essa (incômoda) posição, e não a posição de pesquisador, determinado pelos sentidos do discurso científico (literato)? Será que ele já experimentou essa posição na sua vida escolar? Será que isso lhe foi oportunizado?

Este trabalho então, partindo dessas questões já postas, vai buscar compreender a constituição da autoria na universidade, através da análise da discursividade que sustenta os sentidos nessa instituição.

2 Introduzido por Henry (1975 apud Gallo 2001), o preconstruído designa aquilo que remete a uma construção anterior e exterior, independente, por oposição ao que é construído pelo que é enunciado. Segundo Gallo (2001, p.4), o preconstruído dá conta dessa presença do outro, que não é o outro enunciativo, nem o outro interdiscursivo, o primeiro, pontual demais, o segundo, amplo demais. "O préconstruído é o outro do interdiscurso, circunscrito em uma região histórica e ideológica, delimitada no acontecimento do discurso”. 


\section{AS DISCURSIVIDADES DA UNIVERSIDADE}

\section{O Discurso Pedagógico}

Orlandi (2003) distingue três tipos de funcionamento discursivo com base na relação entre o objeto do discurso, seus interlocutores e a linguagem. São eles o discurso lúdico, polêmico e o autoritário. O discurso lúdico é aquele em que os sentidos estão abertos, há predominância de polissemia. O objeto (referente) está exposto à presença dos interlocutores e cada um deles pode produzir sentido sobre este objeto. O discurso polêmico é aquele no qual os interlocutores procuram controlar a polissemia. Os participantes não se expõem, ao contrário, procuram dominar o seu referente, dando-lhe uma direção, indicando perspectivas. Por fim, o discurso autoritário se caracteriza pela contenção da polissemia por um agente exclusivo, que pretende ser único e oculta o referente pelo seu dizer. Não há interlocução: “O exagero é a ordem no sentido em que se diz “isso é uma ordem”, em que o sujeito passa a instrumento de comando. Esse discurso recusa outra forma de ser que não a linguagem”(Orlandi, 2003).

A partir dessa tipologia, Orlandi (2003) caracteriza o discurso pedagógico (DP) como discurso predominantemente autoritário, em que há um trabalho de ocultamento do referente pela contenção extremada da polissemia. O resultado é um efeito de evidência, como se os sentidos aí formulados fossem óbvios. Este funcionamento traz como conseqüência um discurso alheio a questionamentos em que há somente um agente exclusivo.

Assim, imaginariamente, a interlocução pedagógica compõe-se de um emissor (agente exclusivo do dizer), que é o professor. Este ensina (inculca) a ciência (objeto/referente) para o ouvinte, que é o aluno, através da escola. Não há uma interrelação entre locutores. Existe apenas um emissor que é o professor, que "sabe", e, portanto, tem o direito de ensinar. Ao aluno resta receber esse ensinamento, pois é aquele sujeito que não sabe e está na escola para aprender. Para Orlandi (2003), o aluno ao ser ensinado pelo professor sofre interdições. Exemplos disso são as provas e os exercícios em cuja formulação se enuncia: "responda". São questões denominadas "questões objetivas" que levam os alunos a responderem já cerceados pelos enunciados. A autora usa a noção "hipertrofia da autoridade” para designar a gradação na relação de autoritarismo na escola, sendo que o professor está no topo desta hierarquia, o que permite que ele produza um discurso individualizado em seu aspecto estilístico com perguntas diretas e sócio-cêntricas como, por exemplo: Não é verdade?, Percebem?, Certo? 
Neste contexto, resta ao aluno repetir o que o professor diz, construindo, assim, a mesma imagem que o professor faz do referente do discurso: uma representação de ciência apagada pelo conhecimento de certa metalinguagem e pela apropriação que o professor faz do cientista.

Essa voz assumida pelo professor é formulada em outra instância, na da ciência. À escola, resta reproduzi-la, ocultando sua fonte. O conhecimento repassado pelo professor assim se constitui num simulacro de cientificidade, pois ao tomar para si o que está no discurso da ciência, o professor o faz como se originasse dele. O dizer desvinculado de sua fonte se organiza como se tivesse uma origem em si mesmo, ou seja, na voz do professor. Orlandi (2003) diz que o estabelecimento desse efeito de cientificidade é observado em dois aspectos: na metalinguagem e na apropriação do cientista feita pelo professor.

Para a autora, o problema da metalinguagem está na sua memória que fica subsumida: fixam-se as definições e excluem-se os fatos: “Através da metalinguagem estabelece-se o estatuto científico do saber que se opõe ao senso comum, isto é, constrói-se com a metalinguagem o domínio da objetividade do sistema” (Orlandi, 2003, p. 30). Assim, o DP se resume em uma linguagem que dilui seu objeto, cristaliza sua metalinguagem e as razões em torno de seu referente se reduzem ao “é porque é.” Determinado pelo DP o professor toma posse dessa metalinguagem e se apropria do cientista sem se mostrar como fonte mediadora. O professor se torna a fonte detentora daquele conhecimento. Apaga-se o modo pelo qual o professor se apropriou do conhecimento. No DP, assim, o referente, que é a ciência, não está aparente e sim oculto, é da ordem do não-dito.

\section{O Discurso Científico}

O discurso científico (DC), referente/objeto do DP, assim como todo discurso, é uma prática histórica e ideologicamente determinada. Não é o indivíduo que produz conhecimento científico, e sim toda uma sociedade e a sua história, levando-se em conta o modo e as relações de produção que as constituem. Isto implica aceitar que o conhecimento científico não se origina de uma atividade solitária, de um único sujeito alheio ao seu tempo e a sua época, mas sim do que Pêcheux (1988) chama de condições ideológicas de 
reprodução/transformação das condições de produção ${ }^{3}$. Estas condições repercutem na forma de relações de desigualdades-subordinação, que determinam os interesses históricos de cada época.

O DC também pode ser classificado como um discurso autoritário na sua relação interdiscursiva, pois na sua relação com outros discursos, com o discurso do "senso comum”, por exemplo, é o DC que domina o referente, aquele que lhe impõe o sentido. É por isso que está no campo da certeza, da manifestação de um saber supremo. Convence o outro (discurso) a aceitá-lo como absoluto, já que por meio de resultados empíricos e de dados estatísticos cria-se um efeito de verdade, limitando a possibilidade de dúvida. O efeito de sentido do DC como detentor da verdade, além da "força" dos argumentos, dá-se, também, pelo caráter formal da produção. É por isso que, para Coracini (1991), o caráter assertivo do discurso científico não dá margem a questionamento. O enunciador coincide com o pesquisador, que se reveste de autoridade: “Afinal, quem poderia duvidar das afirmações de um cientista que colheu seu material, observou-o com base em seus princípios teóricos e metodológicos rígidos e “inquestionáveis”, atingindo determinado resultado?” (Coracini, 1991, p. 123). Por outro lado, o DC pode ser considerado menos autoritário intradiscursivamente, já que a relação entre os interlocutores é marcada por um grau menor de irreversibilidade. Isso se deve ao fato de o cientista e de seus pares procurarem, cada um a seu modo, dominar o referente, dandolhe uma direção, indicando perspectivas ${ }^{4}$. Há nesse funcionamento uma relativa autonomia na medida em que, ao incorporar a voz do conhecimento, cada cientista pode elaborar, manipular e modificar relativamente o saber estabelecido. Mostra disso são as diferentes correntes científicas que concorreram e se transformaram ao longo da construção do que denominamos conhecimento científico na nossa sociedade. Além disso, o DC funda os seus sentidos sobre

\footnotetext{
${ }^{3}$ As condições de produção compreendem a instância verbal da produção do discurso (sujeito(s) que enunciam num tempo e num espaço) e a conjuntura sócio-histórico-ideológica que regulam as relações de força das instituições em uma sociedade como a nossa. Existe, também, segundo Orlandi (1999), um mecanismo imaginário que faz parte das condições de produção, o qual produz imagens dos sujeitos, do objeto do discurso, dentro de uma conjuntura sócio-histórica. Assim, o modo como o sujeito se vê, como o sujeito vê quem fala, e também como vê o objeto do discurso são conseqüência do jogo dessas imagens.

4 Orlandi (2003, p. 243), tratando especificamente do discurso religioso, afirma que nesse último fala a voz de Deus - sendo que a voz do padre ou de qualquer pregador representa a voz de Deus. E o modo de representação destes sujeitos (Deus e padre/pregador) caracteriza-se pelo baixo grau de autonomia do padre/pregador com relação à voz de Deus que nele fala. Desse modo, o discurso religioso não apresenta nenhuma autonomia dos interlocutores, pois o representante da voz de Deus, o padre, não pode modificá-la de nenhum modo. Já no caso do discurso político, observa-se um outro funcionamento na relação interlocutiva. Há uma maior independência, uma autonomia razoável. Segundo Orlandi (2003), o político não só é autônomo em relação à voz do povo a qual representa, "como ele pode até mesmo criar, inventar a voz do povo que lhe for mais conveniente. Desde que lhe seja atribuída legitimidade.” (Orlandi, 2003, p. 245).
} 
seu objeto que é a ciência. É um discurso que, nos termos de Foucault (1987), instaura uma discursividade, ou seja, produz enunciados que vão ecoar na história produzindo coisas-asaber. São exemplos de discurso fundador, além do DC, o religioso, o literário, o jurídico.

Contudo, é preciso destacar que a comunidade científica que perpetua o DC, forma-se também no interior de universidades e centros de pesquisas. Sendo assim, há um espaço no sistema educacional para o funcionamento do DC e a universidade, portanto, é o lugar do DC, do DP e de outros discursos, que se constituem ora numa relação de conflito, ora de aliança.

\section{O Discurso Acadêmico}

Assim, o modo de funcionamento do DC encontra apoio na maneira como se organiza a comunidade científica, que tem a universidade e outros centros de pesquisa como seu espaço institucional. Além disso, para Zamboni (2001, p. 33), a ciência:

encontra seu lugar social na produção de papers, [...] se constitui num fazer discursivo-argumentativo que não "descobre" os fatos científicos (como se eles existissem a priori) pré-existentes em algum lugar oculto da natureza, mas cujo fazer é constitutivo da própria rotina de produção que os gera.

Nesta rotina geradora de materiais científicos das universidades, vemos funcionar também o que denominamos Discurso Acadêmico (DA). Esse discurso, mesmo organizado de forma a produzir normatizações, estatutos, através de um sistema disciplinarizado e seriado que determina uma gradação no modo como se adquire o conhecimento, indicando sua relação de aliança com o DP, vai, no que diz respeito ao modo como produz sentidos sobre a ciência, se mostrar diferentemente do DP.

No DA se mantém a presença do referente (a ciência não está oculta), já que os participantes (alunos, professores, pesquisadores) procuram dominar o referente, “dando-lhe uma direção, indicando perspectivas particularizantes pelas quais se olha e se diz, o que resulta na polissemia controlada” (Orlandi, 2003, p.15). Este modo singularizado de construir o referente, em que cada participante busca dominá-lo, se mostra enuncitativamente através de marcas explícitas de heterogeneidade: os enunciadores são marcados nos textos (monografias, papers) através do discurso relatado. O professor no DA não se apropria da voz do cientista sem explicitar o seu lugar de mediador. Nesse discurso, é o cientista que ocupa a posição de educador. O DA, assim, é um tipo de discurso polêmico. 
Relacionando essa discussão com os materiais monográficos produzidos pelos alunos, observamos que, numa instituição de ensino, a produção de trabalhos desse tipo vai ser regulada, então, pela articulação dos discursos pedagógico, científico e acadêmico. Nessa conjuntura heterogênea, a luta pelo sentido se dá por meio de relações discursivas ora em conflito, ora em aliança. Por um lado, nos trabalhos dos alunos determinados pelo DP, a ciência é tratada como um simulacro. Os sentidos do discurso científico são transformados pelo DP, que, na sua função de intermediário, constrói uma metalinguagem própria, que, mesmo apresentando-se como “objetiva” e “neutra”, não é a mesma do DC. O aluno, nesse contexto, produz sentidos parafrásticos que não lhe garantem um lugar de autonomia com relação aos dizeres do DC. Os materiais de pesquisa produzidos por este aluno serão por isso, também, simulacros.

De outro modo, se considerarmos que a escola, especificamente a universidade, se constitui também pelo DA, esperaríamos que o modo de produção dos trabalhos dos alunos se diferenciasse. De fato, os trabalhos exigidos nos cursos de graduação como, por exemplo, a monografia, sendo mais afetados pelo DA do que pelo DP, devem se caracterizar pela formulação de sentidos menos parafrásticos sobre ciência, já que a relação de interlocução (professor/cientista/aluno) é passível de reversibilidade. O referente (a ciência) estaria vulnerável e qualquer um dos sujeitos poderia lhe garantir um sentido. No DA o aluno pode, em determinadas condições, ser aquele que detém o saber.

Isto posto, surge uma questão incontornável e que parece contradizer a aceitação de um discurso com as características do DA na universidade, que é a própria produção monográfica destes alunos. Na maioria dos casos, esses materiais se constituem por textos parafrásticos, em que o aluno “não sabe” o que dizer. Além disso, a possibilidade de autoria por parte do aluno sofre uma transgressão quando encontramos nesse material o plágio.

\section{AUTORIA}

Ao perguntarmos o que é um autor, precisamos, primeiramente, distingui-lo do sujeito do discurso. Esse último, não vai ser entendido enquanto indivíduo, mas enquanto uma inscrição em um espaço histórico e ideológico que é determinante para o modo como esse sujeito dá sentido ao que lhe rodeia. É por isso que Pêcheux (1988 apud Orlandi, 1999, p.17) 
vai afirmar a relação constitutiva entre sujeito e ideologia: "não há discurso sem sujeito e não há sujeito sem ideologia: o indivíduo é interpelado em sujeito pela ideologia e é assim que a língua faz sentido".

Já a autoria é compreendida por Foucault (1996) como um processo que vem se desenvolvendo desde a época medieval dando autoridade e qualificando a verdade, principalmente no discurso científico: "Na ordem do discurso científico, a atribuição a um autor era, na Idade Média, indispensável, pois era um indicador de verdade” (Foucault, 1996, p.27). Ainda hoje, pede-se que o autor responda por suas produções, por seu texto, para que se instaure a credibilidade e, consequentemente, para que se possa lhe garantir o sentido.

Foucault (1987) relaciona sujeito e autoria, dizendo que autor é uma das funções enunciativas que o sujeito assume enquanto produtor de linguagem. É a instalação, no discurso, da evidência de um sujeito submetido às variadas determinações que organizam o espaço social da produção de sentidos. Contudo, para Foucault (1987), pode haver discursos como conversas, receitas, decretos que precisam somente de quem os assine, não de um autor. Sendo assim, para ele, nem todo sujeito é um autor.

Guimarães e Orlandi (1993 apud Orlandi, 1999), ao tratarem dessa questão, propõem um princípio que difere daquele proposto por Foucault (1987), pois enquanto este último diz que a autoria vale somente para alguns tipos de textos, Guimarães e Orlandi (1993 apud Orlandi, 1999) vão afirmar que mesmo não tendo um autor que o assine, qualquer texto poderá ter uma autoria: “em outras palavras, um texto pode até não ter um autor específico mas, pela função-autor, sempre se imputa uma autoria a ele” (Orlandi, 1999, p. 75).

Portanto, enquanto o sujeito é resultado da interpelação do indivíduo pela ideologia, o autor, para Guimarães e Orlandi (1993 apud Orlandi, 1999), é uma representação de unidade e delimita-se na prática social como uma função específica do sujeito. O autor é o lugar em que se constrói a unidade do sujeito. Como o lugar da unidade é o texto, o sujeito se constitui como autor ao constituir o texto em sua unidade, com sua coerência e completude (imaginárias). "O sujeito, diríamos, está para o discurso assim como o autor está para o texto" (Orlandi, 1999, p. 73). O autor é, então, considerado como princípio de agrupamento do discurso.

Para Gallo (2001), a autoria pode ser observada em dois níveis: no nível enunciativodiscursivo e no nível discursivo por excelência. Em ambos os níveis, segundo ela, a autoria 
tem relação com a produção do “novo” sentido e, ao mesmo tempo, é a condição de maior responsabilidade do sujeito em relação ao sentido que reproduz e, por essa razão, de maior unidade. O primeiro nível (enunciativo-discursivo) diz respeito à função de autor, que estabelece a condição de todo sujeito enquanto produtor de texto; já o segundo nível (discursivo por excelência) refere-se ao efeito-autor.

A assunção de autoria pelo sujeito através da elaboração efeito-autor, segundo Gallo (1994), consiste, em última análise, na construção de um sentido e de um "fecho" organizadores de todo o texto. Esse "fecho", apesar de ser um entre tantos outros possíveis produzirá um efeito de sentido único, como se não houvesse outro possível. Dito de outra maneira, esse "fecho" torna-se "fim” por um efeito que faz parecer único o que é múltiplo; transparente o que é ambíguo.

Assumimos aqui a proposta por Guimarães e Orlandi (1993 apud Orlandi, 1999) de que a autoria é função de todo sujeito. Esta assunção torna-se bastante relevante quando relacionada às questões discutidas nesse trabalho: como se dá a constituição da autoria do sujeito aluno produtor de monografias em cursos de graduação quando vale-se dos materiais da internet como fonte de pesquisa. Materiais que vão compor as monografias, mas que não são mencionados como fonte de pesquisa pelos alunos, caracterizando com isso o plágio.

De fato, a aceitação de que todo sujeito é um autor no contexto do plágio parece, inicialmente, contraditório, já que o sujeito plagiador ao se apropriar da voz do outro não estaria construindo este lugar do dizer afetado pela responsabilidade, coerência, unidade. Para tanto, é preciso levarmos em consideração que não basta falar para ser autor, o sujeito precisa “apreender” a assumir o papel de autor e aquilo que daí implica. Orlandi (1999, p.76) chama essa aprendizagem de assunção de autoria:

\footnotetext{
A assunção de autoria implica uma inserção do sujeito na cultura, uma posição no contexto-históricosocial. Apreender a se representar como autor é assumir, diante das instâncias institucionais, esse papel social na sua relação com a linguagem: é mostrar-se como autor.
}

Dessa perspectiva, o aluno plagiador ainda não teria conseguido assumir o seu lugar de autor dentro da instituição universitária, devido a sua incapacidade de lidar com a autoria enquanto função do DA. A função-autor, neste discurso, permite ao aluno certo domínio sobre o referente (saber/ciência), diferentemente do DP, em que a função-autor não garante a ele uma posição que não seja aquela de repetir o que o professor, detentor do saber, diz. Esse 
aluno plagiador estaria sofrendo as coerções do DP mesmo na universidade, lugar por excelência do DA.

\section{MONOGRAFIA, PLÁGIO E INTERNET: UMA LEITURA SOBRE A AUTORIA}

Da perspectiva teórica e metodológica da Análise do Discurso, não se impõe ao analista neutralidade, já que não há análise sem interpretação. $\mathrm{O}$ analista envolve-se na interpretação e portanto,

há que se introduzir um dispositivo teórico, para que o mesmo atue na relação do analista com os objetos simbólicos que analisa, produzindo um deslocamento em sua relação de sujeito com a interpretação, para que ele possa trabalhar entre a descrição e a interpretação. (Orlandi, 1999, p.60)

A delimitação do corpus, por sua vez, não segue critérios empíricos (positivistas), mas critérios teóricos. De tal modo, de acordo com Orlandi (1999, p. 62), não se busca a exaustividade em extensão, nem a completude em relação ao objeto empírico, pois o mesmo é inesgotável. Essa concepção vem do próprio entendimento do discurso que não se fecha em si mesmo e está sempre relacionado/determinado por outros discursos (interdiscurso). Assim, cada análise é entendida como o resultado de um recorte dentre os muitos outros possíveis.

Nesse trabalho, nosso ponto de partida é o acontecimento discursivo materializado em trabalhos de conclusão de curso de graduação/monografias, no qual há trechos retirados da internet sem que seja creditada a fonte. A análise toma como corpus quatro monografias organizadas pelas denominações Aluno 1, Aluno 2, Aluno 3 e Aluno 4. Além desse primeiro recorte, um outro organiza-se a partir de enunciados que materializam a relação do alunoautor-plagiador com o "outro", ou seja, com os enunciados que se constituem entre o dizer do aluno e do "outro autor” não citado. Em outras palavras, diremos que esse recorte é dado pela contradição: homogeneidade/ heterogeneidade do corpus. Observaremos exatamente essa relação contraditória.

O último recorte parte da interdiscursividade que sustenta os dizeres sobre a universidade, ou seja, da circunscrição e convergência dos três discursos: o pedagógico, o acadêmico e o científico. A partir do que se estebeleceu como metodologia, destacamos que os próprios recortes que resultam na delimitação do corpus e no modo como este vai ser analisado através do entendimento de sua interdiscursividade, já é resultado da interpretação; dito de outra maneira, “já é decidir sobre as propriedades discursivas” (Orlandi, 1999, p.63) 
que organizam os sentidos que constituem a relação do aluno-autor-plagiador com o "outro", que faz parte do seu discurso, mas que é apagado pelo aluno.

Isso posto, iniciamos a análise com o Aluno 1. Na sua monografia (texto 1 em itálico), o aluno retira o trecho (1 em negrito) da monografia da autora Carolina Frazon Terra, cujo título é “Tudo pelo Social: a responsabilidade social como uma das atribuições de relações públicas”, localizado no seguinte endereço da internet:

http://gestcorp.incubadora.fapesp.br/portal/monografias/pdf/76.pdf.

\begin{abstract}
Aluno 1 - trecho 1 da Internet
[...]Quando a empresa deixa de cumprir suas obrigações sociais, ela perde seu capital de responsabilidade social, perdendo principalmente, credibilidade, motivação, causando deterioração do clima organizacional.
\end{abstract}

Aluno 1 - trecho 1 da monografia

[...] Quando a empresa deixa de cumprir suas obrigações sociais, ela perde seu capital de responsabilidade social, perdendo principalmente, credibilidade, motivação, causando deterioração do clima organizacional.

No recorte abaixo, da monografia do Aluno 3, o trecho é retirado do artigo científico encontrado no seguinte endereço: http://www.intercom.org.br/papers/xxii-ci/gt10/10b06.PDF.

Aluno 3 - trecho da Internet

[...] A palavra comunicação deriva do latim “comunicare”, cujo significado seria tornar comum, partilhar, trocar opiniões, conferenciar.

Aluno 3 - trecho da monografia

[...] A palavra comunicação deriva do latim "comunicare”, cujo significado seria tornar comum, partilhar, trocar opiniões, conferenciar.

Observamos em ambos os recortes (Aluno 1 e Aluno 3), que os trechos das monografias (em itálico) foram retirados na íntegra dos textos encontrados na Internet (em negrito). Os alunos não consideram o autor original do texto e tomam o trecho como seu na monografia, como se fosse um dizer próprio, deles mesmos. Apagam qualquer rastro que poderia levar ao texto original. Não deixam evidências do texto do outro e nem se mostram marcando de alguma maneira, no material da monografia, a sua presença enquanto autores como vamos observar nos outros recortes. 
No trecho que se segue, novamente da monografia do Aluno 1, o recorte retirado da internet faz parte do artigo da $\operatorname{Prof}^{\mathrm{a}}$ Dr $^{\mathrm{a}}$ Cecília M. Krohling Peruzzo, intitulado "Relações Públicas com a comunidade: uma agenda para o século XXI”, e localizado no seguinte endereço da internet:

http://www.comunicacaoempresarial.com.br/artigocomcorporativaceciliaperuzzo.htm.

Trecho Aluno 1 - trecho da Internet

[...] Como diz Gilles Lipovetsky (1995, p.4) "nossa época, com efeito, não é mais aquela em que uma grande empresa podia se considerar como um agente econômico puro. A grande empresa não vende apenas produtos, ela deve gerar sua relação com o público, produzir e promover sua própria legitimidade institucional. $\mathrm{E}$ isso a fim de reforçar sua marca."

Trecho Aluno 1 - trecho da monografia

[...] A grande empresa não vende apenas produtos, ela deve gerar uma relação com o público, produzir e promover sua própria legitimidade institucional, a fim de reforçar sua marca.

O Aluno 1 ao retirar o trecho da internet, além de ignorar a autoria do artigo intitulado “Relações Públicas com a comunidade: uma agenda para o século XXI”, ignora no artigo, a citação de Gilles Lipovetsky. Assim, entendemos que o Aluno 1 apaga duplamente os autores ao se apropriar do discurso.

No recorte que se segue, novamente a monografia do Aluno 1, observamos que o aluno não considera o autor do texto original, que foi sua fonte de pesquisa na Internet, e toma o trecho como seu, apagando o percurso que poderia levar ao texto original. Contudo, nesse caso, acrescenta enunciados como “Além disso" e “alguns do" (buscando constituir, possivelmente, um lugar de autoria?). O trecho é retirado do mesmo artigo, citado anteriormente, cuja autora é Carolina Frazon Terra:

Trecho Aluno 1 - trecho da internet

[...] Mais do que filantropia aleatória, as chamadas empresas-cidadãs incorporam uma maior sistematização em suas atividades sociais, aliando vocação e estratégia a elas, compreendendo a análise, escolha e determinação de uma causa que tenha relação com os negócios da empresa. Isso faz com que os investidores estratégicos se convertam em valor a marca, imagem positiva junto aos consumidores, fornecedores, clientes e potenciais. As administrações desses projetos sociais mensura os resultados atingidos contribuindo, assim para um ciclo de profissionalização nas organizações privadas e nas entidades beneficiadas.

A responsabilidade social traz a tona o voluntariado empresarial, que estimula os funcionários a participarem dos projetos patrocinados pela empresa. As organizações privadas são as que mais agregam setores de relações públicas. Sendo assim, esses departamentos devem mobilizar eficientemente os recursos da empresa frente a oportunidades e riscos originados interna e externamente a organização. 
Trecho Aluno 1 - trecho da monografia

[...] Mais do que filantropia aleatória, as chamadas empresas-cidadãs incorporam uma maior sistematização em suas atividades sociais, aliando vocação e estratégia a elas, compreendendo a análise, escolha e determinação de uma causa que tenha relação com os negócios da empresa. Isso faz com que alguns dos investidores estratégicos se convertam em valor a marca, imagem positiva junto aos consumidores, fornecedores, clientes e potenciais.

As administrações desses projetos sociais mensura os resultados atingidos contribuindo, assim para um ciclo de profissionalização nas organizações privadas e nas entidades beneficiadas.

Além disso, a responsabilidade social traz a tona o voluntariado empresarial, que estimula os funcionários a participarem dos projetos patrocinados pela empresa.

As organizações privadas são as que mais, agregam setores de relações públicas. Sendo assim, esses departamentos devem mobilizar eficientemente os recursos da empresa frente a oportunidades $e$ riscos originados interna e externamente a organização.

Já o outro recorte, agora do Aluno 2, está relacionado ao artigo científico, cuja autoria é de Celene Fidelis Frias Ferreira. Intitula-se "EVENTOS: área de interesse para os profissionais de Turismo, Relações Públicas e Marketing” e foi encontrado no seguinte endereço da internet: http://www.facef.br/rea/edicao04/ed04_art01.pdf. Observamos aí a troca do enunciado “Alguns” por “outros”, a omissão do enunciado "estes últimos com as mais variadas formações”, o emprego das iniciais maiúsculas em "Relações Públicas” e, ainda, a alteração da pontuação na frase “Não é algo isolado" (ambos os enunciados marcariam a tentativa do sujeito de buscar um lugar de autoria?)

Aluno 2 - trecho da internet

[...] "Outros profissionais que reivindicam a organização de eventos para si, como aqueles com formação em turismo ou os promotores de eventos, estes últimos com as mais variadas formações, visam apenas o retorno financeiro, sem a preocupação própria do profissional de relações públicas que objetiva cuidar do conceito da empresa, pois o evento está inserido num amplo planejamento organizacional; não é algo isolado" CESCA, (1997, p.14).

Aluno 2 - trecho da monografia

[...] Alguns profissionais que reivindicam a organização de eventos para si, como aqueles com formação em turismo ou os promotores de eventos, visam apenas o retorno financeiro, sem a preocupação própria do profissional de Relações Públicas que objetiva cuidar do conceito da empresa, pois o evento está inserido num amplo planejamento organizacional. Não é algo isolado.

Em outro recorte, novamente retirado da monografia do Aluno 1, há, também, o apagamento do seu caminho de pesquisa na Internet e, conseqüentemente, a não identificação do autor do texto do qual ele se utiliza para compor sua monografia. Notamos que, ao longo do seu texto, a descrição é idêntica a do texto original, como se os dados ali apresentados sobre o tema responsabilidade social fossem coletados pelo Aluno 1 e não pela autora do 
artigo científico. O texto foi retirado do artigo “A responsabilidade social no Brasil: uma questão em andamento”, de autoria de Cláudia Souza Passador, no seguinte endereço encontrado na Internet:

http://unpan1.un.org/intradoc/groups/public/documents/CLAD/clad0044201.pdf

Aluno 1 - trecho da internet

[...] Segundo David Cohen13., existem indícios fortes de que as empresas estejam começando a assumir seu lado cidadão. A maioria das empresas (56\%) apóia programas sociais, segundo a primeira pesquisa nacional sobre a atuação social e o estímulo ao voluntariado nas empresas, finalizada em julho/1999 pelo Programa Governamental Comunidade Solidária.

Merece destaque também, como dissemos anteriormente, o impulso dado por Herbert de Souza (Betinho), a partir de 1996, sobre a campanha convocando os empresários a um maior engajamento, com práticas relacionadas ao exercício da responsabilidade social, por meio da divulgação do Balanço Social, como um instrumento de demonstração deste envolvimento14.

A inserção social do grande capital ainda é novidade no Brasil15. De acordo com a GIFE (Grupo de Institutos, Fundações e Empresas), organização não-governamental dedicada à cidadania empresarial, os investimentos sociais no Brasil estão crescendo. De acordo com Ioschpe, diretora da Fundação Ioschpe e ex-presidente fundadora da GIFE, a "filantropia corporativa" é uma característica americana, mas não é brasileira, e, se em certos ambientes (como religiosos) ela tem muito valor no Brasil, o mesmo não acontece no ambiente empresarial, onde o conceito de filantropia corporativa ainda esta em fase de "aculturação".

Para Ioschpe, “a postura como empresa socialmente responsável pode ter inspirações numa matriz filantrópica, mas hoje se distancia dela",17 visto que "filantropia" no grego significa um amor inespecífico à humanidade, e hoje, as empresas desenvolvem uma posição muito mais afinada com seus valores intrínsecos: o lucro e sobrevivência, que investimento social. Entretanto, a empresa apoiando projetos sociais, e tendo essa conduta socialmente responsável, a empresa alavanca recursos e apoio por meio da adesão dos trabalhadores e descobre ganho adicional que vão da melhoria do clima organizacional até a valorização da marca.

Uma pesquisa do Instituto de Pesquisa Econômica Aplicada (IPEA) revelou que 67\% das empresas situadas na região sudeste do Brasil praticaram “ações sociais” no ano de 1998. O IPEA denomina "ações sociais" qualquer doação feita a pessoas ou entidades, sem fins lucrativos, que apóiem a área da saúde, educação e lazer. Verificou-se que há relação direta entre participação das empresas e o tamanho delas: $62 \%$ das microempresas, $76 \%$ das pequenas empresas, $75 \%$ das médias e $95 \%$ das grandes têm atuação social.

A responsabilidade social também toma um novo fôlego no Brasil devido aos modelos que chegam junto às novas organizações aqui fixadas e também pela falta de atuação do Estado em amenizar os problemas sociais.

\section{Trecho Aluno 1 - trecho da monografia}

[...] A maioria das empresas (56\%) apóia programas sociais, segundo a primeira pesquisa nacional sobre a atuação social e o estímulo ao voluntariado nas empresas, finalizada em julho/1999, pelo Programa Governamental Comunidade Solitária. Merecem destaque também, o impulso dado por Herbert de Souza (Betinho), a partir de 1996, sobre a campanha convocando os empresários a um maior engajamento, com práticas relacionadas ao exercício da responsabilidade social, por meio da divulgação do Balanço Social, como um instrumento de demonstração deste envolvimento.

Inserção social do grande capital ainda é novidade no Brasil. De acordo com GIPE (Grupo de Instituições, Fundações e Empresas), organização não governamental dedicada á cidadania empresarial, os investimentos sociais do Brasil estão crescendo. De acordo com Ioschpe, diretora da Fundação Ioschpe e ex-presidente fundadora da GIPE, a "Filantropia Corporativa" é uma característica americana, se em certos ambientes (como religiosos) ela tem muito valor no Brasil, o 
mesmo não acontece no ambiente empresarial, onde o conceito de filantropia corporativa ainda esta em base de culturação.

Para IOSCHPE (1998) [...] a postura como empresa socialmente responsável pode ter inspirações numa matriz filantrópica, mas hoje, as empresas desenvolvem uma posição muito mais afinada com seus valores intrínsecos: o lucro e sobrevivência, que investimento social. Entretanto, a empresa apoiando projetos sociais, e tendo essa conduta socialmente responsável, alavanca recursos e apoio por meio de adesão dos trabalhadores e descobre ganho adicional que vão da melhoria do clima organizacional até a valorização da marca.Uma pesquisa do Instituto de Pesquisa de Economia Aplicada (IPEA) revelou que 67\% das empresas situadas na região sudeste do Brasil praticaram "ações sociais" no ano de 1998. O IPEA denomina "ações sociais" qualquer doação feita por pessoas ou entidades, sem fins lucrativos, que apóiem a área da saúde, educação e lazer. Verificou-se que há relação entre participação das empresas e o tamanho delas; 62\% das microempresas, 76\% das pequenas empresas, $75 \%$ das médias e $95 \%$ das grandes têm atuação social. A responsabilidade social também toma um novo fôlego no Brasil devido aos modelos que chegam junto ás novas organizações aqui fixadas e também pela falta de atuação do Estado em amenizar os problemas sociais. As empresas para que cumpram suas responsabilidades.

Como podemos observar, no texto da monografia do Aluno 1, mais uma vez se repete o duplo apagamento da autoria: apaga-se a autoria do artigo e do autor citado pela pesquisadora no seu texto. É retirado o enunciado "Segundo David Cohen13, existem indícios fortes de que as empresas estejam começando a assumir seu lado cidadão”. Além disso, o aluno não coloca no texto de sua monografia a frase "como dissemos anteriormente", que materializaria enunciativamente a voz da autora no referido texto.

No entanto, as referências aos institutos de pesquisas IOSCHPE e IPEA são deixadas na íntegra, tanto aquelas em discurso direto: “Para IOSCHPE (1998) 'a postura como empresa socialmente responsável pode ter inspirações numa matriz filantrópica, mas hoje se distancia dela'”; quanto as outras, em discurso indireto: “De acordo com a GIFE (Grupo de Institutos, Fundações e Empresas), organização não-governamental dedicada à cidadania empresarial, os investimentos sociais no Brasil estão crescendo” e "De acordo com Ioschpe, diretora da Fundação Ioschpe e ex-presidente fundadora da GIFE, a 'filantropia corporativa' é uma característica americana, mas não é brasileira, e, se em certos ambientes[...]”.

Em outro recorte, agora do Aluno 3, o que merece destaque é a inversão nas ordens das frases do trecho retirado da internet, um artigo de Mariângela Benine Ramos Silva, intitulado "Informação e responsabilidade social das empresas”, com o seguinte endereço da Internet:

http://www.unopar.br/portugues/revista_cientificaj/artigosderevisao/informacao/body_ $\underline{\text { informacao.html }}$

Aluno 3 - trecho da internet 
[...] Os efeitos desejados no público receptor, por meio de uma mensagem eficiente, apta e capaz. Cabe à comunicação dirigida.

Aluno 3 - trecho da monografia

[...] Cabe à comunicação dirigida à elaboração de uma mensagem eficiente, eficaz e apta a produzir os efeitos desejados no público receptor.

Nesse fragmento, o aluno 3, além de apagar o percurso, manipula o trecho invertendo a ordem da frase.

Nos materiais analisados encontramos dois tipos de enunciados: 1) fragmentos que somente apagam o caminho, ou seja, o endereço da internet e o autor original do texto copia/cola; 2) fragmentos que além de apagar o caminho e o autor original, retiram ou acrescentam enunciados no material do outro: a) produzindo uma interpretação do trecho original e b) (re)produzindo uma sutura entre dois discursos. Nos dois casos o efeito é de homogeneização dos sentidos dos diferentes discursos aí concorrentes (em confronto). Mas, no tipo 1, pelo apagamento do “outro” e, no 2, pelo encaixe do “um” no “outro”.

\section{O “OUTRO” NO “UM” E O “UM” NO “OUTRO”}

Dos trabalhos que se inscrevem no que se denominou a terceira fase da Análise do Discurso, destacamos a discussão sobre heterogeneidade feita por Authier-Revuz (1990). A autora afirma que toda fala é determinada de fora da vontade do sujeito, pois o outro como elemento constitutivo do sujeito compartilha com ele o espaço discursivo da enunciação. Authier-Revuz (1990), a partir disso, classifica a heterogeneidade em dois tipos: a constitutiva e a mostrada (marcada e não marcada).

O primeiro tipo relaciona-se ao que Pêcheux (1988) denomina Esquecimento $n^{0} 1$. Segundo o autor, todo sujeito esquece daquilo que determina os sentidos de seu dizer, ou seja, esquece que o seu dizer é resultado da relação entre linguagem e história (memória) e, por isso, ele não é a fonte única do sentido, nem tampouco elemento onde se origina o discurso. O sujeito esquece que o seu discurso é regulado pelo interdiscurso, ou seja, por aquilo "que fala antes, em outro lugar, independentemente". Authier-Revuz (1990), desse modo, assume a noção de heterogeneidade constitutiva como condição sem a qual não há discurso. Esse tipo de heterogeneidade não é evidenciada por marcas lingüísticas explícitas, 
mas é amparada pelos pressupostos psicanalíticos do discurso atravessado pelo inconsciente e pelo interdiscurso.

Já a heterogeneidade mostrada, que se apresenta por marcas lingüísticas explícitas da presença do “outro" no discurso do "um” é, segundo a autora, uma maneira de negociação do sujeito com a heterogeneidade constitutiva. O sujeito dá lugar ao heterogêneo, ao outro, para melhor negar sua presença. Esse acordo se dá sob a forma de denegação: o sujeito (locutor) reformula o seu próprio dizer marcando o seu enunciado com um sentido diferente do que estaria no universo do outro (interlocutor). Como resultado, o sujeito garantiria um efeito de sentido de que o resto do dizer é todo seu, pois ao circunscrever sua alteridade garante uma unidade aparente para o seu dizer. A autoria nesse caso, seria resultado desse imaginário de unicidade e autonomia do sujeito.

A noção de heterogeneidade mostrada marcada pode ser produtiva para a compreensão dos materiais aqui analisados. A negociação do sujeito com as outras vozes que compõem o seu dizer pode ser observada na materialidade lingüística como um conjunto de marcas estruturais, através das quais o sujeito inscreve no seu discurso as palavras do outro, mostrando-as, assinalando-as, quer através das aspas, do itálico, de parênteses ou através de outros recursos gramaticais. Assim, a heterogeneidade mostrada marcada funciona através de um discurso relatado, em que o enunciador ou usa suas próprias palavras para transmitir o discurso do outro (discurso indireto), ou recorta as palavras do outro e as cita (discurso direto), assinalando estas palavras no seu discurso através de “operações locais explícitas” (Authier-Revuz, 1990).

Partindo daí, uma das características observadas nos recortes das monografias analisadas, a inserção ou a troca de enunciados feitas pelo aluno, parece indicar algo como uma heterogeneidade mostrada ao inverso, ou seja, enunciador usa suas próprias palavras para se marcar no discurso do outro e ao se marcar confunde-se com ele. Esse é caso dos enunciados do tipo 2 (a, b), que apresentam marcas do “um” no “outro”. Estas marcas lingüísticas, através das quais os alunos se mostram nos seus textos, vão indicar que este sujeito está interessado em se "posicionar” no texto do qual se apropriou, buscando através dessa estratégia constituir-se como autor desse material. A tentativa do aluno de se marcar no texto do outro produz um efeito de que o dizer seja seu, ou seja, ao acrescentar a sua voz através de marcas lingüísticas explícitas no texto do outro, provoca um efeito de sentido de que ele está na origem daquele dizer. 
Assim, o sujeito sabe imaginariamente do outro, mas ao invés de marcá-lo, marca a si próprio, garantindo que o dizer seja seu. O sujeito aluno precisa, então, mostrar-se no discurso do outro (autor original) para, a partir daí, o discurso tornar-se seu. Há duas formas de fazer isso, seja por meio de uma interpretação do dizer do outro, seja por meio de uma sutura. Essa segunda forma produz um efeito de homogeneização, fazendo desaparecer a heterogeneidade discursiva.

Esse modo singular do aluno se relacionar com as vozes dos "outros" (cientistas, pesquisadores) pode ser entendido como conseqüência do funcionamento da discursividade na Universidade, que envolve a relação entre os discursos pedagógico, científico e acadêmico. Esses alunos estão sendo determinados por um conjunto de dizeres que envolvem tanto DA quanto o DP. O primeiro impõe ao aluno a necessidade de se constituir como pesquisador e, portanto, ter um certo compromisso como a autonomia do seu texto. Já o DP censura esta autonomia do aluno. Neste espaço, o aluno ainda não se (re)conhece enquanto sujeito que pode dizer algo diferente do professor.

Assim, na universidade, se, por um lado, interpelado pelo DA o aluno precisa assumir uma posição enquanto sujeito que tem certa autonomia para se posicionar como autor no discurso científico; por outro lado, interpelado pela autoridade do DP, tem essa autonomia censurada. A posição assumida pelo aluno ao realizar sua monografia é decorrente, justamente, deste funcionamento discursivo conflitante.

O DP que constrói um sentido de “cientificidade” através de uma série de estratégias em que o seu referente (ciência) é ocultado, vai também estabelecer uma relação de irreversibilidade entre locutor/professor e ouvinte/aluno, em que se fixam estas posições de forma categórica. Como conseqüência disso, ao professor é dado o direito de dizer sobre o conhecimento, enquanto ao aluno cabe reconhecer esta autoridade. Os trabalhos escolares feitos pelo aluno, sujeito do DP, refletem um funcionamento discursivo, em que são produzidos sentidos parafrásticos, retornos aos mesmos sentidos controlados pelo dizer legítimo. A função-sujeito assumida por este aluno não lhe garante um lugar de autonomia com relação aos dizeres sobre o saber/ciência.

O material das monografias copiados/plagiados de textos da Internet evidencia essa produção de sentidos parafrásticos em que o aluno, sob as coerções do DP, reproduz um mesmo sentido sobre conhecimento, aquele que ele imagina que o professor sabe. $\mathrm{Na}$ 
monografia do Aluno 1, há trechos retirados da Internet e inseridos em sua monografia na introdução, na revisão teórica e na parte de análise. Já no caso dos trabalhos dos Alunos 2, 3 e 4, os trechos retirados da internet estão na parte da monografia reservados a revisão teórica. Esses fragmentos, classificados como do tipo 1, mostram que os alunos somente apagaram o caminho da pesquisa: o endereço da internet e o autor original do texto - copia/cola.

A revisão teórica, em uma monografia, é o lugar onde se procura destacar o que já foi escrito sobre o tema. Caracteriza-se a teoria que vai sustentar a pesquisa, além de rever criticamente o que já foi dito sobre o tema estudado. Busca-se com isso produzir movimentos que possam acrescentar, complementar as pesquisas já realizadas sobre o assunto evitando duplicação de esforços e pesquisas que digam a mesma coisa. Nesse "lugar”, o aluno precisa compreender a posição dos outros autores e a sua posição enquanto autor de um texto que fala sobre os “outros”. No entanto, é aí que o aluno se mostra como não tendo nada a dizer (DP funcionando); evidência disso, é o trabalho de cópia feito pelos alunos dos textos de outros pesquisadores.

Ao mesmo tempo, sendo levado pelo DA a se mostrar como pesquisador, inventor, o aluno tenta construir uma posição que represente a função-autor dentro do DA. A funçãoautor, nesse discurso, permite ao sujeito/aluno certo domínio sobre o referente (saber/ciência), diferentemente do DP, em que a função-autor não garante ao aluno uma posição que não seja aquela de repetir o que o professor diz. Esta tentativa de construção da autoria determinada pelo DA pode ser observada no material analisado quando o aluno, ao produzir sua monografia, busca construir no "texto do outro" um lugar para o seu dizer. Exemplos disso, são os enunciados acrescentados ou alterados através de processos parafrásticos nos textos retirados da Internet (tipo 2), em que além de apagar o caminho e o autor original, retiram ou acrescentam enunciados no material do outro ou produzindo uma interpretação do trecho original ou (re)produzindo uma sutura entre dois discursos.

Esse modo de assunção de autoria por parte do sujeito/aluno do DA pode ser entendido também através do efeito-autor (Gallo, 1994), o qual garante a construção de um sentido de "fecho" para o texto. Esse sentido de "fim" decorre do reconhecimento da autoridade do aluno sobre o seu dizer. Esse poder também lhe permite produzir algum deslocamento, algum movimento na unidade e na não-contradição que é efeito da funçãoautor. Conseqüentemente, no DP não vemos se produzir o efeito-autor, pois o aluno enquanto autor (função-autor) nesse espaço discursivo, não tem autonomia para determinar onde o seu 
dizer começa e termina. Dessa perspectiva, além de compreendermos a autoria como efeito de coerência, não-contradição e de responsabilidade por parte do sujeito (função-autor), vamos também considerá-la como um efeito de produção de novo sentido (efeito-autor).

Isso posto, podemos afirmar que as diferentes formas do sujeito aluno se colocar como autor estão relacionadas com o modo da assunção de autoria, ou seja, se há ou não efeitoautor. Os diferentes modos que compõem a tomada de posição do sujeito autor no contexto histórico-social da universidade resulta em uma assunção de autoria em que o aluno assume de forma mais ou memos "nova" e autônoma a responsabilidade pelo que diz. Na caracterização dos diferentes modos da autoria, levando em consideração a autonomia do sujeito para inovação e ineditismo, podemos dizer que no DP essa autonomia da autoria do aluno tende a zero. No DP, há uma tentativa de estacar a reversibilidade da relação dos interlocutores: há somente um “agente exclusivo” do dizer que é o professor. O objeto sobre o qual se fala, a ciência, é transformada pela mediação (ciência/professor/aluno) em definições e conclusões exclusivas. Enquanto autor, assim, o aluno vai ter um compromisso com a unidade e coerência, mas não lhe é requerido nenhum dizer inédito.

Já no DA há certa autonomia do aluno que se posiciona de forma a assumir a responsabilidade de tratar da ciência de forma menos parafrástica. A forma inédita do dizer passa pela manutenção da presença do referente do discurso (o conhecimento, a ciência não está oculta como no DP), sendo que os participantes procuram dominar esse referente de modo a dar-lhe uma direção, "indicando perspectivas particularizantes pelas quais se olha e se diz, o que resulta na polissemia controlada” (Orlandi, 2003, p. 15). Este modo de construir o referente em que cada participante busca dominá-lo indica que o autor, neste discurso, domina certos mecanismos discursivos que lhe permitem algum deslocamento, alguma ruptura de sentidos e, por conseguinte, algum trabalho polissêmico.

O problema do plágio, neste caso, é a conseqüência de uma conjuntura educacional em que se relacionam diferentes discursos determinados por uma interdiscursividade que vai ela mesma produzir, através de encadeamentos e articulações, a delimitação entre os discursos pedagógico, acadêmico e científico e, conseqüentemente, certa posição de autoria. Assim, o DA aqui ganha seus contornos a partir da sua relação com os discursos científico e pedagógico. O DA responde a uma relação de aliança com o DP quando funciona a partir de normalizações, de estatutos, de um sistema disciplinarizado e seriado, em que a produção de um material como uma monografia de final de curso de graduação é exigência. Contudo, ao 
mesmo tempo, dele se afasta pelo modo como produz sentidos sobre ciência, funcionamento que o aproxima do DC.

O DC, por sua vez, é aquele que garante o pré-construído tanto para o discurso pedagógico como para o acadêmico: é sobre ciência que eles falam. Há no funcionamento da autoria no DC uma relativa autonomia na medida em que, ao incorporar a voz do saber/conhecimento, o cientista pode elaborar, manipular e modificar relativamente o saber estabelecido. Dito de outra forma há no DC certa disputa pelo sentido, resultando, nos termos de Orlandi (1999), em uma polissemia controlada, já que o referente (o fato, o real) é disputado pelos interlocutores. Podemos dizer, a partir disso, que a produção do novo sentido é elemento, em certa medida, constitutivo da assunção de autoria no DC, ou seja, tem-se nesse discurso a produção do efeito-autor. Observamos, a partir disto, que a autoria no DA decorre de sua relação de aliança com o DC, sendo que, mesmo funcionando na mediação: ciência/professor/aluno, o DA, determinado pelo DC, vai garantir uma certa disputa pelo referente (pelos sentidos da ciência).

Entretanto, o que também particulariza, ou seja, compõe interdiscursivamente o DC, é sua relação com os outros discursos que constituem a universidade. Assim, afetado pelo DP, o DC pode responder, como sugere Coracini (1991), a certo jogo de interesse e de poder que se acha velado em nome do saber academicista, ou seja, observa-se um jogo altamente subjetivo na medida em que se apresenta com o discurso argumentativo e de convencimento. E isto se dá de acordo com Coracine (1991, p.46), graças à opacidade da linguagem que permite a ilusão da aproximação efetiva do real, já que sem a interferência do sujeito (neutro) e da ideologia (sentido é obvio), o DC alcança o objetivo a que se propõe: o de convencer o interlocutor da verdade (aparente) que enuncia.

Queremos enfatizar, com isso, que os discursos não se constituem isoladamente, mas num processo de fechamento e deslocamento, em que é justamente a “zona de contato” a garantia de particularização de cada discurso:

...podemos dizer que o interdiscurso é a relação de um discurso com outros discursos. No sentido de que esta relação não se dá a partir dos discursos já particularizados. É ela própria a relação entre discursos que dá a particularidade, ou seja, são as relações entre discursos que particularizam cada discurso. (Guimarães, 1993, apud Orlandi, 1996, p. 68) 


\section{CONSIDERAÇÕES FINAIS}

A universidade se institui por uma dispersão de discursos em que se destacam o pedagógico, o acadêmico e o científico. A circunscrição desses discursos se dá por um processo de deslocamento de suas fronteiras e cada um se constitui a partir do reagenciamento dos sentidos do outro.

De fato, no DP a ciência é resignificada e transformada em simulacro, já que por certo uso da metalinguagem, vai apenas "falar sobre" o seu referente (a ciência) transformando-o em sentidos didatizados, que se garantem por certa textualização: definições rígidas, encadeamentos automatizados que levam às conclusões exclusivas (Orlandi, 2003). Além disso, o DP gera um apagamento da voz do cientista pelo professor. As posições de autoria, do professor e do aluno são diferenciadas, fixas e resguardam a autoridade e o poder do professor. Neste quadro, o aluno não é visto e nem se vê como sujeito responsável pelo saber (ciência), como alguém que tem a capacidade de questionar, criticar, refletir. No DP, assim, no que diz respeito à posição de autoria do aluno, não se produz o efeito-autor.

O DA, por seu turno, vai dentro do sistema educacional se constituir produzindo outras relações com a ciência, já que professor e aluno podem assumir a posição de pesquisador. Além disso, não há o apagamento da interlocução que converge para o ocultamento do referente (conhecimento). Nesse discurso, portanto, ao se produzir um texto, um paper, é necessário explicitar a posição do(s) outro(s) (citações dos “outros” artigos e dos “outros” pesquisadores), e tanto o autor como o “outro” lutam para dar sentido ao referente. Essa delimitação do “outro”, que garante imaginariamente ao autor que o resto do dizer é somente seu (Authier-Revuz,1990), garante uma constituição da autoria que se dá pela formulação de um efeito de unidade (função-autor). Já o funcionamento polêmico em que os interlocutores podem, a seu modo, dar sentido ao referente, possibilita a produção de um “novo” sentido (efeito-autor).

O que garante esse funcionamento para DA é a sua relação de aliança com o DC. E é na universidade, mais que em outra instância do sistema educacional, que se estabelecem as condições materiais para que o aluno possa se representar enquanto um pesquisador. A monografia de final de curso é este lugar de representação do aluno enquanto autor. Contudo, a universidade também é espaço afetado pelo DP. 
E é nesta instituição de práticas discursivas contraditórias que se encontra o aluno autor das monografias aqui analisadas: interpelado pelo DA, o aluno é levado a se posicionar como autor que pode e deve dizer o que é ciência (efeito-autor); de outro modo, interpelado também pelo DP, não é capaz de se tornar visível como um sujeito que tem autonomia para dizer.

Do que nos interessa destacar, que é a relação entre autoria e plágio, diríamos que os materiais analisados materializam os diferentes modos de assunção de autoria: os enunciados do tipo 1 (fragmentos que somente apagam o caminho, ou seja, o endereço da internet e o autor original do texto - copia/cola) o fazem marcando a autoria no seu grau mínimo, ou seja, o mais próximo possível do DP. Já os enunciados do tipo 2 (fragmentos que, além de apagar o caminho e o autor original, retiram ou acrescentam enunciados no material do "outro: a) produzindo uma interpretação do trecho original e b) (re)produzindo uma sutura entre dois discursos) materializam em um grau intermediário a assunção de autoria, que poderia ir ao extremo por meio de um posicionamento do sujeito, o qual se delimitaria através da heterogeneidade mostrada marcada. Nesse caso, observamos uma aproximação com o DC.

O plágio é, portanto, uma conseqüência dessa conjuntura, ou seja, é resultado dessa discursividade contraditória que torna o aluno incapaz de se (re)conhecer como esse autor que pode dizer e se dizer, dentro da escola, da universidade. Na produção dos trabalhos exigidos nos cursos de graduação, dos quais destacamos a monografia, o aluno é interpelado pelo DA a assumir a posição de um sujeito pesquisador com certa autonomia, com certa autoridade sobre o seu próprio dizer. No entanto, a análise mostrou que, em muitos casos, a própria produção monográfica destes alunos pode se constituir de textos parafrásticos (plagiados). Os textos científicos (artigos, monografias) funcionam apenas como apoio, semelhante ao apoio que o professor busca nos livros didáticos. O aluno, assim, não sabendo o que dizer, busca nas vozes dos outros os sentidos para construir o seu dizer, e como no livro didático essa voz é apagada:

\footnotetext{
Infelizmente o Discurso Pedagógico [...] não contempla a autoria. Assim, para preencher essa posição vazia o sujeito-aluno coleta conteúdos vindos de qualquer lugar, porque nessa condição de autoria esvaziada não importa muito de onde vem o conteúdo. O aluno não reconhece a autoria porque ele não exerce essa função. (Gallo, 2004, p. 15)
}

A internet, portanto, não é um destruidor da educação dos “tempos modernos” e muito menos um problema para o sujeito pesquisador, pois, como afirma Gallo (2004, p. 17), ele “já é autor de saída”. A internet é, para esse sujeito, aliada, é apenas uma nova maneira de 
pesquisa. O plágio, neste caso, segundo Gallo (2004, p. 17), é a impossibilidade de estar de fato nesse lugar de autoria, e esse “é apenas o sintoma, o que se pode ver: a ponta do iceberg”.

\section{REFERÊNCIAS}

Authier-Revuz, J. (1990). Heterogeneidade(s) Enunciativa(s). Cadernos de Estudos Lingüísticos, 19, Campinas.

Brandão, H. N. (1998). Subjetividade argumentação polifonia: A propaganda da Petrobrás. São Paulo: Editora da UNESP.

(2002). Introdução à análise do discurso. Campinas: Editora da Unicamp.

Castanho, L. M. (Org.). (2000). Pedagogia universitária: A aula em foco. Campinas: Papirus.

Coracini, M. J. R. (1991). Um fazer persuasivo: O discurso subjetivo da ciência. Campinas: Educ. Pontes.

Foucault, M. (1996). A ordem do discurso. $7^{\text {a }}$ ed. São Paulo: Loyola.

(1987). A arqueologia do saber. Tradução de Luiz Felipe Beata Neves. Rio de Janeiro: Forense Universitária.

Freire, P. (1996). Pedagogia da autonomia - Saberes necessários à prática educativa. Rio de Janeiro: Paz e Terra. Coleção Saberes.

Freire, P. (1985). Por uma pedagogia da pergunta. Rio de Janeiro: Paz e Terra.

Freire, P. (1983). Pedagogia do oprimido. $12^{\mathrm{a}}$ ed. Rio de Janeiro: Paz e Terra.

Gallo, S. L., Martins, M. F. \& Morello, R. (2008). Linguagens, ciências e tecnologias na formulação do conhecimento. In: S. Braga et al. (Orgs). Ciência da linguagem: Avaliando o percurso, abrindo caminhos. Blumenau: Nova Letra.

Gallo, S. L. (2001). Autoria: questão enunciativa ou discursiva? Linguagem em (Dis)Curso, 1(2), 63-70. Tubarão: Editora da UNISUL.

(2004). Plágio na Internet. In: R. Morello (Org.). Giros na cidade: Materialidade do espaço urbano. Campinas: LABEURB/NUDECRI - UNICAMP. (1994). Discurso da escrita e ensino. Campinas: Editora da UNICAMP.

Orlandi, E. (1996). Interpretação. Petrópolis: Vozes. (1999). Análise do discurso: Princípios e procedimentos. Campinas: Pontes. 
Pontes.

(2003). A Linguagem e seu funcionamento: As formas do discurso. Campinas:

Campinas: Pontes.

(2004). Interpretação: Autoria, leitura e efeitos do trabalho simbólico. $4^{\mathrm{a}}$ ed.

Pêcheux, M. (1988). Semântica e discurso: Uma crítica à afirmação do óbvio. Campinas: Editora da UNICAMP.

Pêcheux, M.; Fuchs, C. (1975). A propósito da análise automática do discurso: Atualização e perspectivas. In: F. Gadet \& T. Hak (Orgs.) (1997). Por uma análise automática do discurso: Uma introdução à obra de Michel Pêcheux. Tradução de Péricles Cunha. Campinas: Editora da UNICAMP.

Rauen, F. J. (1999). Elementos de iniciação à pesquisa. Rio do Sul: Nova Era.

Zamboni, L. M. S. (2001). Cientistas, jornalistas e a divulgação científica: Subjetividade e heterogeneidade no discurso de divulgação científica. Campinas: Autores Associados.

\section{AS AUTORAS}

Marci Fileti Martins é Lingüista, Profa. Dra. da Pós-Graduação em Ciências da Linguagem da Unisul, Palhoça, SC. Atua na área da Lingüística e Comunicação. É editora da revista digital de divulgação científica Ciência em Curso

(http://aplicacoes.unisul.br/cienciaemcurso/revista/index.html).

E-mail: marci.martins@unisul.br.

Carolina Neotti possui graduação em Comunicação Social - Relações Públicas pela Universidade do Vale do Itajaí (2002), pós-graduação em Publicidade e Propaganda pela Universidade do Vale do Itajaí (2004) e mestrado em Ciências da Linguagem pela Universidade do Sul de Santa Catarina (2007). Tem experiência na área de Comunicação, atuando principalmente em comunicação organizacional, marketing, mercado, ensino, plano de comunicação estratégica, eventos. E-mail caroneoti@yahoo.com.br 